$\angle$ Research Square
Preprints are preliminary reports that have not undergone peer review.

They should not be considered conclusive, used to inform clinical practice, or referenced by the media as validated information.

\title{
Multivesicular bodies and their roles in cancer progression
}

\section{Xueqiang Peng}

Liang Yang

Yingbo Ma

Yan Li

Hangyu Li

\section{Video Byte}

Keywords: Cell Communication and Signaling, multivesicular body, MVB, extracellular vesicles, amphisome, autophagy, trafficking, release, cancer, exosome, biogenesis, fate, pathology, tumor progression, intraluminal vesicle, endosomal sorting complex required for transport, ESCRT, posttranslational modification, PTM, maturation

Posted Date: November 11th, 2020

DOI: https://doi.org/10.21203/rs.3.rs-106621/v1

License: (c) (i) This work is licensed under a Creative Commons Attribution 4.0 International License. Read Full License 


\section{Abstract}

These tiny sacs within cells are called multivesicular bodies, or MVBs. Once considered nothing more than a part of the cell's waste disposal and recycling system, MVBs are now understood to play multiple important roles, including promoting tumor progression. MVBs selectively load substances such as lipids, proteins, and nucleic acids, and then fuse with the cell membrane to release their payloads outside the cell in the form of exosomes. In tumors, the key proteins involved in MVB formation, transport, and fusion are abnormally expressed, and evidence suggests that MVBs promote virtually all aspects of cancer progression - from tumor expansion to drug resistance. For example, MVBs direct the cellular degradation needed for cancer cells to form the finger-like projections that help them spread to other organs, and studies show that MVB cargoes can transfer cancer drug resistance from one cell to another. Understanding the full functional repertoire of MVBs could help further clarify their roles in cancer progression and could lead to more powerful anti-cancer therapies. 